\title{
LA VIS EXPANSIVA DE LOS DERECHOS FUNDAMENTALES Y SU INCIDENCIA EN LA CONFIGURACIÓN Y EXIGIBILIDAD DE LOS DERECHOS SOCIALES'
}

\author{
The expansive effects of fundamental rights \\ and its incidence on the configuration and enforceability \\ of social rights
}

\author{
JOSÉ IGNACIO CUBERO MARCOS \\ Universidad del País Vasco/Euskal Herriko Unibertsitatea \\ joseignacio.cubero@ehu.eus
}

Cómo citar/Citation

Cubero Marcos, J. I. (2017)

La vis expansiva de los derechos fundamentales y su incidencia en la configuración y exigibilidad de los derechos sociales. Revista Española de Derecho Constitucional, 110, 105-140 doi: https://doi.org/10.18042/cepc/redc.110.04

\section{Resumen}

El Tribunal Europeo de Derechos Humanos (TEDH) y, en menor medida, el Tribunal Constitucional (TC) ha dotado a determinados derechos fundamentales de un contenido cada vez más amplio, obligando a las autoridades públicas a actuar en determinadas circunstancias para su efectivo reconocimiento y eficacia. Todo ello ha contribuido a perfilar derechos de corte social, considerados en la Constitución española (CE) como principios rectores de la política social y económica. Así, resulta imposible que se garantice la vida privada y familiar si las autoridades no adoptan medidas alternativas o proporcionadas para que se facilite una vivienda a una familia. Del mismo modo, no proveer la asistencia sanitaria adecuada puede conllevar

1 Este artículo se enmarca en el proyecto investigación de título Derecho Administrativo, Medio Ambiente, Ordenación del Territorio y Derechos Humanos, financiado por el Departamento de Educación, Universidades e Investigación del Gobierno Vasco correspondiente a los grupos consolidados del Sistema Universitario Vasco. 
tratos inhumanos o degradantes por las autoridades públicas. El objetivo del trabajo consiste en poner de manifiesto que ese contenido de los derechos fundamentales ha de ser efectivo y obligatorio para las autoridades internas, tanto para el legislador, la Administración como para los tribunales de justicia, cuando se susciten dudas en la resolución de conflictos.

\title{
Palabras clave
}

Derechos humanos; derechos sociales; interdependencia y proporcionalidad.

\begin{abstract}
The European Court of Human Rights and, to a lesser extent, the Constitutional Court has interpreted certain fundamental rights with a more extensive content, enforcing public authorities to take positive measures in some circumstances, so that those rights can be recognized and be effective. That has had an influence on the configuration of social rights, considered as guiding principles of the economic and social policies according to the Constitution. Thus, it is impossible to guarantee private and family life if authorities do not take alternative or proportional measures to provide housing to a family. In the same way, if the authorities do not provide an adequate healthcare, they can inflict torture or other cruel, inhuman or degrading treatment or punishment. The goal of the work consists in showing that the fundamental rights' content, as interpreted by European Court, has to be fulfilled by internal authorities, such as the legislator, courts and public Administration, when they have any doubt to resolve conflicts.
\end{abstract}

\section{Keywords}

Human rights; social rights; interdependence and proporcionality. 


\section{SUMARIO}

I. INTRODUCCIÓN. II. ORIGEN Y CARACTERIZACIÓN DE LOS DERECHOS SOCIALES. III. INDIVISIBILIDAD E INTERDEPENDENCIA DE LOS DERECHOS HUMANOS: 1. Las necesidades básicas. 2. Las posturas doctrinales hacia la integración. 3. La perspectiva social actual. IV. EL DEBATE EN TORNO A LA EXIGIBILIDAD DE LOS DERECHOS SOCIALES Y SU INTEGRACIÓN CON LOS DERECHOS CIVILES Y POLÍTICOS: 1. La definición del objeto del derecho. 2. La expansión de los derechos fundamentales en diferentes ámbitos: żuna respuesta sesgada a la integración y sus consecuencias jurídicas?: 2.1. Asistencia sanitaria. 2.2. Medio ambiente. 2.3. Vivienda. V. LAS CONSECUENCIAS JURÍDICAS EN EL DERECHO ESPAÑOL: 1. La aplicabilidad directa y las medidas de acción positiva. 2. La necesidad de atender la doctrina por parte de los órganos jurisdiccionales españoles. 3. La actuación de los poderes públicos en la ponderación de los derechos en presencia. VI. CONCLUSIONES. BibliogRAFía.

\section{INTRODUCCIÓN}

El motivo principal que empujó al autor a abordar este tema es la dramática situación en la que se encuentran millones de personas en el mundo, debido a la falta de recursos, de alimentación y a la satisfacción de unas condiciones de vida que ameriten su calificación como seres humanos. El origen de esta tragedia radica en la creciente desigualdad que ha ido consolidándose en las últimas décadas y que los poderes públicos no pueden ignorar so pretexto de argumentos económicos o jurídicos, como la intervención previa del legislador. El objeto de este artículo consiste en definir la influencia que ejerce una interpretación expansiva, efectuada desde instancias jurisdiccionales internacionales, de determinados derechos fundamentales para, asimismo, dotar de un contenido determinado a derechos sociales o principios rectores de la política social y económica, tal y como los ha calificado el texto constitucional. ¿Se trata de una conexión lógica, basada en criterios jurídicos, o, más bien, responde esta tendencia jurisprudencial a una realidad social que no puede ser ignorada?

Como no podía ser de otro modo, estas diferencias sociales se han reflejado en dramáticas escenas de desalojos, el incremento de la asistencia en alimentación, pobreza infantil y dificultades para recibir el suministro de un 
servicio esencial en un hogar como la electricidad ${ }^{2}$. La restricción en el gasto público, motivada por el endeudamiento y una política monetaria muy restrictiva de las instituciones europeas, ha supuesto la deficiente prestación de servicios públicos de una indudable importancia en la cohesión social y en el desarrollo de las personas, como son la sanidad y la educación.

El trabajo tiene por objeto explicar y describir la expansión de los derechos fundamentales cuando su contenido se halla vinculado a los derechos de corte social, como la vivienda o la asistencia sanitaria. En primer lugar, se pone de manifiesto la interdependencia, conexión y universalidad de los derechos fundamentales y sociales; segundo, se presenta el debate relativo a la exigencia judicial y tutela de los derechos sociales; tercero, tratará de demostrarse la siguiente tesis: mediante la expansión de los derechos fundamentales, algunas instancias internacionales han propugnado la necesidad de trascender los dictados de las legislaciones internas para afrontar problemas de justicia social. El instrumento que emplean es la ponderación y el test de proporcionalidad evaluando caso por caso los derechos e intereses en colisión, sin mostrar una preferencia o prioridad previa por ninguno de ellos.

\section{ORIGEN Y CARACTERIZACIÓN DE LOS DERECHOS SOCIALES}

La teoría de los derechos sociales ha discurrido por un camino distinto respecto de los considerados derechos civiles o políticos, o derechos de primera generación. La razón estriba en la poderosa influencia de la burguesía y las concepciones filosóficas que reafirmaban la preponderancia del individuo, sus derechos, capacidades o propiedad frente a los intereses de clase, ya sea la nobleza o los gremios ${ }^{3}$. La subjetividad y una visión del mundo más abierta permitieron apuntalar las bases del liberalismo, cuyos impulsores e ideario forjaron las bases del Estado de derecho. Su principal misión consistía en proteger los derechos de las personas y garantizar su ejercicio libre de interferencias $^{4}$. Se ha afirmado que el advenimiento de las teorías marxistas y la lucha de clases empujó a los poderes públicos a adoptar medidas no con el objeto

2 Véase http://www.unicef.es/sites/www.unicef.es/files/infanciaespana/unicef_informe_ la_infancia_en_espana_2014.pdf.

Véase El Plural, 7 de junio de 2014, en torno a la asistencia alimentaria o el diario El Mundo de 3 de julio de 2014, acerca de la pobreza energética.

3 Pérez Luño (2010: 230).

4 Abramovich y Courtis (2004: 51). El interés de la sociedad ha llevado a los poderes públicos a limitar el derecho de propiedad y a establecer controles. 
exclusivo de impedir las injerencias en los derechos de las personas, sino para que los poderes públicos intervinieran y llevaran a cabo prestaciones al objeto de consolidar un modo de vida acorde a la dignidad de la persona. Se ha señalado el carácter colectivo de ese tipo de derechos, en tanto en cuanto respondía a las demandas de grupos sociales especialmente afectados por los efectos de un sistema en el que el ser humano tan solo formaba parte del engranaje productivo que tenía por objeto generar capital5.

Resulta insostenible la idea del derecho social alejada de la dignidad de la persona y de su autonomía, entendida como el libre desenvolvimiento en relación con sus congéneres y entorno ${ }^{6}$. La oposición entre Estado y sociedad civil carece de sentido, en tanto en cuanto la democracia no puede permitir que las personas que habitan en una comunidad se vean privadas de las necesidades esenciales e inherentes a cualquier ser humano, lo que conforma su dignidad ${ }^{7}$. Se ha afirmado la imposibilidad de invocar en la vía judicial directamente los derechos sociales. Su tutela se vería restringida por la ausencia de concreción acerca del derecho y de las facultades que pueden ejercer los titulares ${ }^{8}$. Como señala el art. 53.3 CE, depende del reconocimiento en la vía legislativa, reglamentaria y su interpretación por los tribunales de justicia. Simplemente informan al legislador, como si el grado de vinculación fuera más reducido. Al respecto, se ha establecido en diferentes textos internacionales la indivisibilidad de los derechos humanos y su interdependencia, lo que significa que en el ordenamiento jurídico no existe un limbo o una laguna que deban cubrir los tribunales mediante sus sentencias?.

Asimismo, no encuentra demasiado sentido la distinción del derecho social respecto al civil o político exclusivamente por la necesidad de que aquel precise una intervención previa del legislador y, en el resto, la ausencia de

5 Pérez Luño (2010: 232). La redistribución de la riqueza por parte de los estados se basa en el ejercicio de la política fiscal a diferentes niveles.

6 González Amuchastegui (2004: 388). El desarrollo del individuo en sociedad se ha planteado como el gran reto desde las corrientes racionalistas y su visión del individuo como elemento en torno al cual gira la aplicación del derecho.

7 García Schwarz (2011: 57). Aboga por la complementariedad de los derechos y la caracterización de los derechos fundamentales como derechos de prestación.

8 Rodríguez De Santiago (2007: 40). La regulación de los derechos sociales se lleva a cabo conforme a un criterio social de protección del más débil en el contrato de trabajo.

9 Escobar Roca (2012: 486). Allí donde no estén satisfechas las necesidades básicas, no hay actuación libre y responsable y, por tanto, no ha lugar la cuestión moral. Solo es moralmente imputable el sujeto cuyas necesidades básicas estén cubiertas. 
interferencia o intervención no legítima. Los derechos civiles y políticos, además de necesitar una acción positiva de los poderes públicos, también deben ser concretados y definidos caso por caso por los tribunales, habida cuenta de su enorme abstracción ${ }^{10}$. Piénsese en los retos que presentan hoy las nuevas tecnologías respecto al ejercicio de la libertad de expresión o la intimidad. Sin un desarrollo legislativo o una interpretación jurisdiccional ad casum, no podrían resolverse los numerosos conflictos que suscita el ejercicio de aquellos derechos ${ }^{11}$. Todo ello los aproximaría a los caracteres propios de los derechos civiles y políticos, como la irreversibilidad o su carácter inmanente al ser humano ${ }^{12}$.

\section{INDIVISIBILIDAD E INTERDEPENDENCIA DE LOS DERECHOS HUMANOS}

\section{LAS NECESIDADES BÁSICAS}

Ha de partirse de la tesis relativa a que los derechos humanos deben entenderse como un haz de facultades que impida la privación de la dignidad de la persona y su desenvolvimiento en sociedad. De hecho, la CE reconoce la dignidad como un valor supremo del ordenamiento jurídico y contempla la existencia de un estado social y democrático de derecho. No por el hecho de ser un concepto jurídico indeterminado la dignidad queda en una suerte de estado etéreo sin conexión con el ordenamiento jurídico ${ }^{13}$.

A partir de aquí, los mecanismos de exigencia y reconocimiento de los derechos sociales sufrieron una fractura que se plasmó en textos constitucionales

10 Abramovich y Courtis (2004: 128 y 129). Afirman que no existen obstáculos insalvables para la exigibilidad de los derechos sociales. Se impide la aplicación de criterios políticos.

11 Moreno González (2002: 185). Aboga la autora por una suerte de vinculación negativa del legislador respecto a los derechos sociales o principios rectores de la política social y económica, de modo que el control de la constitucionalidad de las lees también ha de basarse en ese contenido propio del derecho social que alberga el texto constitucional. A favor, Rodríguez De Santiago (2007: 47). El carácter vinculante de los principios rectores ostenta un carácter mediato.

12 Abramovich y Courtis (2004: 95). La protección de datos o los nuevos cauces para ejercer la libertad de expresión, como Internet, exigen nuevas respuestas que, si no las aporta el legislador, han de proceder de la actividad judicial en la interpretación caso por caso.

13 Ferrari (1989: 213). 
que distinguían entre categorías de derechos. Unos que podrían ser invocados ante la jurisdicción, los civiles y políticos, mientras que los sociales requerirían la interpositio legislatoris y, en consecuencia, dependían de la formación política hegemónica para un mayor o menor reconocimiento ${ }^{14}$. La interdependencia e indivisibilidad de los derechos humanos son conceptos que surgieron con posterioridad entre la doctrina jurídica y otros textos internacionales, con motivo de la creciente desigualdad entre seres humanos de diferentes partes del planeta ${ }^{15}$.

El interrogante que suscita todo ello es cómo se concretan la dignidad y la autonomía individuales. Se planteó, en su momento, el concepto de mínimo vital y, en la actualidad, se ha ido perfilando en torno a las llamadas necesidades básicas. Estas últimas permitirían crear el elemento de conexión entre la percepción liberal del individuo, es decir, su libertad y autonomía, y la dignidad propia del ser humano ${ }^{16}$. Es cierto que se estaría fijando un patrón de comparación y que podría incurrirse en una variabilidad tal que, finalmente, la determinación de la necesidad básica quedaría en manos del ámbito econó$\mathrm{mico}^{17}$. De la misma filosofía liberal no se desprende la existencia de un límite y concepto ligado a la necesidad ${ }^{18}$. En este planteamiento moral o valorativo late la justicia social, la distribución racional de la riqueza y, en último término, ciertos aspectos de la igualdad material, al menos en lo que se refiere a ese umbral mínimo ${ }^{19}$.

Las necesidades comportan ciertos criterios valorativos o morales, y deben atravesar el cedazo de la democracia, es decir, deben contar con la libre

14 Gavara de Cara (2010: 34).

15 Uvin (2004: 29). En el fondo, las declaraciones de los textos internacionales de la ONU resultan vagas y dependen de diferentes conceptos de desarrollo: derecho humano, sostenible. Se aboga por la indivisibilidad e interdependencia de los derechos humanos.

16 Pisarello (2007: 43). La dignidad no puede separarse del derecho social. Se reconocería el derecho a recibir aquellos recursos que permiten una vida libre de la dominación de los otros y la posibilidad de definir con otros el sentido de la comunidad en condiciones de aproximada igualdad.

17 González Amuchastegui (2004: 405).

18 Nino (1989: 213). El enfoque no es subjetivo, en tanto parte del valor de la autonomía personal, que es independiente de las preferencias que los individuos puedan tener por tal autonomía. También es objetiva: la valoración de los bienes instrumentales para preservar y expandir la autonomía en la elección y materialización de los planes de vida. Incluso, es posible hacer una jerarquización objetiva de esos bienes tomando en cuenta el parámetro de la frecuencia y el grado de necesidad o relevancia que tiene el bien en cuestión.

19 Rawls (1979: 115). 
aceptación de los individuos, de principios para guiar sus acciones y actitudes frente a acciones de otros ${ }^{20}$. Ahora bien, no puede ignorarse el hecho de que la dignidad de la persona, o su autonomía, se encuentra íntimamente relacionada con la inviolabilidad o la no injerencia, especialmente en los derechos de otras personas. Si el Estado interviene distribuyendo riqueza mediante criterios de justicia social, con la dignidad como el objetivo último, probablemente otras personas pueden sufrir una merma en sus derechos o se les puede restringir ${ }^{21}$. Piénsese, por ejemplo, en la presión fiscal o en la exigencia de deberes para emprender una actividad económica al objeto de reducir el impacto ambien$\mathrm{tal}^{22}$. Este conflicto de intereses que los poderes públicos deben resolver mediante ponderación será objeto de un estudio más detenido con posterioridad.

En la UE, el criterio no cambia en exceso, puesto que se les ha atribuido a los Estados miembros un enorme margen de apreciación para decidir políticas sociales y otorgar o denegar derechos ${ }^{23}$. De hecho, podría afirmarse que todos ellos han configurado o modulado su contenido mediante resoluciones caso por caso o mediante la legislación. Se entendería con ello que solamente el legislador ha de tomar la decisión, sin advertir que la CE también ejerce una función de límite para el legislador y que los principios rectores de la política social y económica revisten una virtualidad como normas constitucionales ${ }^{24}$. A todo ello debe añadirse la eficacia de la Carta de Derechos Fundamentales de la Unión Europea.

\section{LAS POSTURAS DOCTRINALES HACIA LA INTEGRACIÓN}

Ante la insuficiencia del criterio legislativo para garantizar, en último término, la dignidad personal, deviene indispensable acogerse a fundamentos axiológicos, en concreto, a los valores y necesidades vitales que se han venido afirmando históricamente a través de las luchas y revoluciones promovidas por las diversas generaciones ${ }^{25}$. Ahora bien, se ha considerado que todos los

20 Nino (1989: 109). La moral se caracteriza, a tenor del autor, por operar a través del consenso. Si un principio moral constituye una razón para actuar para alguien, él mismo constituye una razón para todos los que se encuentran en las mismas circunstancias relevantes.

21 Kleimt (1979: 63-72).

22 Nazet-Allouche (2006: 223).

23 Órdoñez Solís (2006: 206 y 207). Véase, también, Palmer (2009: 93).

24 Escobar Roca (2012: 513) y Torres Del Moral (2014: 61).

25 Ferrajoli (2001: 372). La fundamentación no reside en alguna ontología ética o en una racionalidad abstracta, sino, más bien, en los valores y las necesidades vitales que 
bienes colectivos, que sirven como medio para ejercer el derecho individual, dependen de la teoría normativa subyacente ${ }^{26}$. Ha de tomarse especial consideración por los grupos minoritarios o más vulnerables que pueden ser sujetos a discriminación. Personas que se encuentran sometidas a las instituciones y que no pueden satisfacer sus necesidades por sí mismas ${ }^{27}$.

Entre la doctrina parece acogerse una suerte de integración, pero fundándose en parámetros distintos. Así, la base del deber de asistencia no es cierto principio liberal de justicia distributiva, sino, más bien, la propia concepción ideal de la sociedad de los pueblos, integrada por sociedades bien ordenadas, de tal suerte que cada pueblo sea miembro pleno y autosuficiente de la sociedad de los pueblos ${ }^{28}$. La autonomía y la libertad de los individuos precisan cubrir necesidades mínimas y, para ello, se necesitaría un consenso que otorgue legitimidad a las actuaciones de los poderes públicos ${ }^{29}$. Eso significaría vivir por encima del umbral de la pobreza y disfrutar de una alimentación imprescindible para un crecimiento físico y mental y para la actividad física, así como un grado de higiene que no dañe la salud de las personas ${ }^{30}$.

El derecho no crea los derechos humanos. Su labor está en reconocerlos, convertirlos en normas jurídicas y garantizarlos también jurídicamente ${ }^{31}$. El ejercicio de la libertad sería impensable sin igualdad jurídica, moral y de oportunidades, por lo que un Estado que no garantizase esos mínimos requisitos

se han venido afirmando históricamente a través de las luchas y revoluciones promovidas por las diversas generaciones de sujetos excluidos $\mathrm{u}$ oprimidos que en cada momento han reivindicado su tutela como condiciones de unos niveles mínimos de igualdad, democracia, integración y pacífica convivencia.

26 Alexy (1997: 190). El carácter universal de medio de los derechos individuales no puede fracasar más que por problemas normativos. Un derecho individual que es exclusivamente un medio para un bien colectivo no puede, por definición, desarrollar frente a este ninguna fuerza propia. Si el derecho pierde su carácter de medio para el bien colectivo o impide su realización, entonces ya no hay ninguna razón para la existencia de ese derecho.

27 Eide (2001: 19 y 20). Especial consideración de los grupos minoritarios o más vulnerables que pueden ser sujetos a discriminación. Personas que se encuentran sometidas a instituciones y que no pueden satisfacer sus necesidades por sí mismas (detenidos, discapacitados, presos). Además, personas que pueden estar afectadas por conflictos bélicos, en que el derecho humanitario complementa la protección ordinaria de los derechos humanos.

28 Rawls (1998: 73).

29 Habermas (2002: 98).

30 Eide (2001: 133 y 134).

31 Uvin (2004: 55). 
estaría vaciando de contenido los derechos humanos ${ }^{32}$. No se trata de invocar la naturaleza humana como un concepto metafísico que condicione u obligue a todas las personas. La construcción de los derechos humanos parte de una visión social y política que trata de promover la dignidad ${ }^{33}$. En el ordenamiento jurídico español, pese a que la CE los califica como principios rectores, los poderes públicos no pueden desentenderse de esa significación o contenido y han de articular jurídicamente todos esos principios rectores, puesto que algunos textos internacionales han previsto el derecho a disfrutar de los derechos sociales ${ }^{34}$.

Desde la perspectiva del Estado democrático, los derechos nacen de la participación de la ciudadanía y de sus demandas y necesidades ${ }^{35}$. No se trata únicamente de una visión patrimonial que entronca con el derecho de propiedad. La autoridad pública debería hacer frente a los conflictos que se suscitan en la misma sociedad y que se convierten en una confrontación por los valores e ideologías ${ }^{36}$.

\section{LA PERSPECTIVA SOCIAL ACTUAL}

Aquellas disquisiciones teóricas encuentran un acomodo perfecto en el contexto actual. La crisis económica ha incrementado sensiblemente la fractura social y la desigualdad, si bien ya se había percibido la progresiva merma de la capacidad económica de grupos sociales más amplios como consecuencia de la confianza ciega en el libre mercado impulsada desde las

32 Fernández (1984: 125). Señala que el ejercicio de la libertad depende de la igualdad moral, jurídica y de oportunidades, pero resulta imposible donde existan y persistan unas estructuras socioeconómicas extremada y profundamente desiguales, pues, en ese caso, los derechos personales y políticos se convierten en algo casi vacío de contenido.

33 Gregg (2013: 46). El autor llega a afirmar que los derechos humanos, como tales, no son inherentes a la naturaleza humana, sino que son consecuencia de una visión política que trata de promover la dignidad. No se necesita invocar una naturaleza humana metafísica que condicione a las personas con una ontología moral que justifique los derechos humanos.

34 Jimena Quesada (2012: 1515).

35 Pisarello (2007: 17).

36 Donnelly (2013: 45). Llega a afirmar que los poderes políticos, por sus estructuras de dominación y poder, acaban vulnerando los derechos sociales, de modo que los derechos humanos pueden proveer un punto esencial para conseguir un consenso o negociar el reconocimiento mutuo. 
instituciones públicas ${ }^{37}$. Así, la estrategia neoliberal, consistente en la preponderancia de las decisiones procedentes de los agentes económicos, ha desarticulado muchos mecanismos de que disponía el Estado para hacer frente a la pobreza o la falta de recursos que permitan desenvolverse con dignidad para cubrir necesidades vitales ${ }^{38}$. La premisa debe partir de la consideración de la persona con independencia de su posición en la estructura de mercado y productiva y debe atenderse exclusivamente a la garantía de su dignidad ${ }^{39}$.

Ese mismo modelo neoliberal ha procurado nichos de cuasiesclavitud en los que se trabajan largas jornadas para obtener salarios ínfimos y la explotación infantil resulta habitual ${ }^{40}$. La libre competencia también ha de sujetarse a límites que responden a demandas o derechos sociales y, en definitiva, la dignidad del ser humano no debería soslayarse frente a las pretensiones o derechos patrimoniales ${ }^{41}$. El conflicto que late en la sociedad entre los valores propios de una economía de libre mercado y las necesidades básicas o garantías mínimas para la dignidad de la persona impide a priori primar unas garantías sobre otras, sino ponderarlas y convertirlas en muchos casos en interdependientes o colaborativas ${ }^{42}$. Esta labor de ponderación requiere una actuación de los Estados, porque se ha demostrado que el exceso de flexibilidad o la falta de intervención de los mercados han impedido el reconocimiento y efectiva implantación de los derechos sociales ${ }^{43}$. El valor humano del sufrimiento se halla al margen de la lógica de los mercados ${ }^{44}$.

En definitiva, los derechos sociales se hallan entreverados y deberían complementarse con los derechos fundamentales, y la interpretación del texto constitucional no puede dejar al albur del legislador de turno la facultad de su

37 Jimena Quesada (2012: 1521).

38 Noguera Fernández (2014: 67).

39 Triguero Martínez (2012: 71). El carácter fundamental de un derecho debe provenir de su consagración jurídico-positiva en normas que gocen de la consideración de fundamentales en el seno del estado social y que, por ende, inciten a la totalidad de los operadores jurídicos a maximizar los mecanismos de protección, exigibilidad y garantía por medio de nuevas interpretaciones o reformas con base en este postulado.

40 Marks (2010: 195) y McBeth (2010: 149).

41 Courtis y Abramovich (2004: 53).

42 Lasa López (2012: 110 y 111).

43 Kinley (2009: 192 y 193). Al tratarse de mercados internacionales, el problema se centra en que existen dificultades para aprobar una legislación transnacional que solucione el problema relativo a la violación de los derechos humanos.

44 Donnelly (2013: 232). 
reconocimiento y efectividad ${ }^{45}$. Los conflictos entre los valores, derechos e intereses exigen un análisis caso por caso y una solución acorde a una ponderación previa entre los mismos. Si eso significa sacrificar ciertos derechos o intereses en beneficio de otros, los poderes públicos no pueden desentenderse y menos en un momento en que se han alcanzado insospechadas cuotas de desigualdad y pésimos niveles de desarrollo humano. Ahora bien, desde una perspectiva jurídica ha de abordarse la exigibilidad ante instancias jurisdiccionales.

\section{EL DEBATE EN TORNO A LA EXIGIBILIDAD DE LOS DERECHOS SOCIALES Y SU INTEGRACIÓN CON LOS DERECHOS CIVILES Y POLÍTICOS}

\section{LA DEFINICIÓN DEL OBJETO DEL DERECHO}

La doctrina clásica ha considerado únicamente exigibles los derechos fundamentales, mientras que los derechos sociales, ubicados en el capítulo III del título II CE, llamados principios rectores de la política social y económica, no deberían invocarse directamente, sino únicamente en virtud de la intervención del legislador (art. 53.3 CE) ${ }^{46}$. Del texto constitucional parece desprenderse esta conclusión y, sin embargo, buena parte de la doctrina entiende esta interpretación superada, al menos parcialmente ${ }^{47}$. Por una parte, se ha cuestionado el valor o virtualidad de tales principios rectores, si bien podrían aplicarse e incidir directamente en la actuación de otros poderes públicos, como el del legislador ${ }^{48}$. Habría de analizarse, aun así, si la vinculación posee

45 Escobar Roca (2012: 374).

46 Como ejemplo, véanse las SSTC relacionadas con la actualización de las pensiones o, en su caso, la congelación. Se atiende a criterios de índole económica, de modo que la actualización de la revalorización de las pensiones puede ser modulada por la Ley de Presupuestos Generales del Estado en función de las circunstancias económicas concurrentes, pues esa actualización suponía únicamente una expectativa (entre otras, SSTC 49/2015, FJ 2.o y 127/2015, FJ 2.o.).

47 Corriente Córdoba (2000: 130 y 131).

48 García Schwarz (2011: 81). Ha de apostarse por un concepto de derecho social con virtualidad y eficacia jurídica, de forma que no se dependa del argumento económico. Véase, también, Escobar Roca (2012: 364). que afirma que el Estado social, como tal, ha de aplicarse como una norma jurídica más, pues no hay una relación de jerarquía entre el Estado de derecho y el democrático. 
un sentido negativo, que también ha reconocido cierta doctrina, o si puede ampliarse el horizonte o alcance interpretativo de los principios, de tal forma que de ellos pudiera derivarse una intervención obligatoria por parte del legislador ${ }^{49}$.

El derecho positivo actual parece reconducir todo hacia cauces puramente formales, es decir, a la posibilidad de invocar el derecho, sin que, en ciertos casos, sea posible su pleno reconocimiento. Así, sucede frecuentemente el conflicto entre derechos, como la libertad de expresión y el derecho a la información, o entre este y el derecho a la imagen. La colisión se halla repleta de matices relacionados con los hechos, los intereses y los derechos de otras personas. La colisión entre los derechos económicos de corte individual y los derechos sociales exige una intervención de los poderes públicos al objeto de promover la igualdad y autonomía del individuo. Todo ello debería comportar, asimismo, una redistribución de los recursos ${ }^{50}$.

La exigibilidad judicial de los derechos fundamentales, con arreglo al ordenamiento jurídico español, no necesariamente se halla relacionada con su objeto, con su grado de definición o concreción, sino que depende de un criterio formal o, tal vez, de su importancia. Los principios rectores de la política social y económica poseen un valor jurídico, una eficacia que puede ser invocada o alegada en tanto forman parte de un texto legal como la $\mathrm{CE}^{51}$. La cuestión a solventar aquí consiste en determinar el alcance de esos principios y su conexión o complementariedad con los derechos fundamentales.

La complementariedad con los derechos civiles y políticos no conlleva siempre armonía o equilibrio, pero el juicio valorativo debe apoyarse en razonamientos jurídicos, y en una ponderación en torno a los perjuicios causados a los titulares de los derechos o, en su caso, en los beneficios obtenidos por ellos. En ocasiones, la definición de los derechos sociales, como la alimentación, la vivienda o la salud, se halla contemplada en compromisos internacionales o en declaraciones que, pese a su carácter orientativo y no vinculante, permitirían establecer un estándar o patrón que debería ser tomado en consideración por las instancias jurisdiccionales cuando examinan la supuesta vulneración de un derecho fundamental ${ }^{52}$. Aquella complementariedad se ha

49 Rodríguez De Santiago (2007: 47).

50 Pisarello (2007: 45).

51 Añón Roig et al. (2002: 103).

52 Durán y Lalaguna (2007: 117-121). Cuando se habla de derechos sociales, se hace referencia a bienes de las personas. No sería adecuado que las políticas sociales se alejasen de esta conceptualización como bienes de las personas. 
plasmado en resoluciones del TEDH que ha preferido llevar a cabo un análisis de ponderación frente a la aplicación estricta de la legalidad.

\section{LA EXPANSIÓN DE LOS DERECHOS FUNDAMENTALES EN DIFERENTES ÁMBITOS: ¿UNA RESPUESTA SESGADA A LA INTEGRACIÓN Y SUS CONSECUENCIAS JURÍDICAS?}

La jurisprudencia, especialmente la emanada del TEDH, ha vinculado los derechos reconocidos en el Convenio Europeo a otros ligados más bien a prestaciones o actuaciones positivas de los poderes públicos, que pueden encuadrarse en los derechos sociales ${ }^{53}$. Se trata de la denominada protección por Ricochet. En su origen tenía por objeto dotar de amparo a sectores de población más vulnerables a violaciones de sus derechos, con lo que se colmaban las lagunas mediante la interpretación extensiva o por conexión con otros derechos fundamentales ${ }^{54}$. Se aborda, a continuación, el análisis de algunos ámbitos en los que se han asimilado los derechos reconocidos en el convenio a otros de corte más social, como la vivienda, el medio ambiente o la asistencia sanitaria.

\subsection{Asistencia sanitaria}

Uno de los paradigmas en torno a la influencia de los derechos sociales en a la vida de las personas se encuentra en las operaciones por cambio de sexo. El TEDH ha confirmado la necesidad de que, en ocasiones, el Estado afronte los gastos derivados de las estas intervenciones quirúrgicas. El derecho a la vida privada y familiar resulta vulnerado en los supuestos en que aquel obstaculiza o, simplemente, no colabora en el cambio deseado por cualquier ciudadano, que resulta imprescindible para el desarrollo de su personalidad y su vida privada. No obstante, el TEDH considera necesario examinar en cada caso si el Estado puede permitirse cubrir la operación, aunque sea parcialmente ${ }^{55}$. La condición de transexual obliga a las autoridades públicas a adoptar medidas administrativas, tales como el cambio en la inscripción del Registro Civil o la modificación del documento de identidad ${ }^{56}$.

\footnotetext{
53 Morte Gómez y Salinas Alcega (2009: 381-383).

54 Sudre (2012: 690).

55 STEDH de 11 de septiembre de 2007, asunto 27527/2003, L. vs. Lituania, apdo. 97.

56 STEDH de 11 de julio de 2002, asunto 25680/1994, I. vs. Reino Unido, apdos. 45-53 El respeto de la vida privada de las personas debería tener en cuenta la realidad
} 
Resulta curioso el argumento relativo a la necesidad de proteger la vida privada y familiar como requisito imprescindible para el desarrollo de la personalidad. Parece desprenderse que a las personas no transexuales no les afecta el hecho de no recibir atención médica en el desarrollo de la personalidad, lo cual parecería poco menos que paradójico. La pregunta que podría suscitarse aquí es por qué se extiende a las personas transexuales y no a otras ${ }^{57}$. El TEDH ha planteado objeciones a la prestación sanitaria universal o a muchas personas, como la viabilidad económica para hacer frente a este tipo de intervenciones por parte de la sanidad pública ${ }^{58}$. Aun así, él mismo parece definir qué mal o deficiencia merecen tratamiento sanitario público, lo que extraña al tratarse, en principio, de una cuestión de mera legalidad a resolver por el Estado, como efectivamente reconoce el TEDH, de acuerdo con criterios económicos, entre otros ${ }^{59}$.

Respecto al derecho a la integridad física, se han establecido algunos requisitos para recibir asistencia sanitaria. En concreto, podría suceder que las personas inmigrantes afectadas sufrieran una dolencia grave que pudiera costarles la vida y, sin embargo, por su situación y estatus jurídico en el país de acogida no pueden exigir de las autoridades públicas un tratamiento ${ }^{60}$. En una controversia planteada ante el TEDH, un ciudadano de Uganda, que residía de forma irregular en Reino Unido, había manifestado que era portador del virus VIH, por lo que solicitó la prestación sanitaria debido a que la repatriación a su país iba a suponer la desatención. Al respecto, el TEDH no garantiza la atención de cualquier persona en todo caso, equiparando integridad física a salud, sino que exige ciertos requisitos ligados al principio de proporcionalidad, es decir, a la necesidad imperiosa de la prestación por los poderes públicos ${ }^{61}$.

Primero, el tratamiento en el país de origen de la persona no debe resultar viable y disponible. Piénsese que, aunque se trate de personas procedentes de zonas subdesarrolladas, pueden facilitar la medicación necesaria para el

médica, biológica y psicológica, manifestada inequívocamente por la recomendación de los expertos médicos, a fin de evitar el retraso en este tipo de operaciones quirúrgicas por cambio de sexo (STEDH de 11 de enero de 2009, asunto 29002/06, Schlumpf $v$ s. Suiza, apdos. 115-117).

57 Courtis y Abramovich (2004: 89).

58 De Lora y Zúniga (2009: 69-73).

59 Santamaría Arinas y Bolaño Piñeiro (2015: 64).

60 Palmer (2009: 55).

61 Arruego (2009: 292 y 293). 
tratamiento y disponen de algunos recursos indispensables ${ }^{62}$; en segundo lugar, la enfermedad ha de resultar lo suficientemente grave como para deteriorar la salud de la persona de forma progresiva o causar daños a terceras personas $^{63}$; tercero, el deterioro de la salud ha de encontrarse en un avanzado estado $^{64}$. En un reciente fallo se ha tratado la cuestión relativa a la obligatoriedad de atender a personas que solicitan el asilo político, especialmente cuando la atención se precisa por menores enfermos, incluso después de que se haya dictado una orden de expulsión. Piénsese en la posibilidad de que se presente un recurso contra el fallo administrativo o jurisdiccional y en el ínterin esas personas necesitan ser asistidas ${ }^{65}$.

Podría considerarse, sin embargo, que la atención médica en los países menos avanzados no comporta de por sí una asistencia adecuada. En ese caso, solamente podría permanecer la persona extranjera en el país de acogida en circunstancias excepcionales, es decir, cuando se halle enfermo de forma crítica y esté próximo a la muerte ${ }^{66}$. El juicio ponderativo que llevan a cabo aquellos pronunciamientos no tiene en cuenta el desarrollo de la personalidad, la autonomía o dignidad, pero sí se colige de ellos que, en realidad, no debería haberse invocado el derecho a no recibir tratos crueles, inhumanos o degradantes (art.3 CEDH), sino el derecho a la vida, por la necesidad de que exista un riesgo de muerte o la enfermedad se encuentre en una situación avan$\operatorname{zada}^{67}$. Podría reclamarse el derecho a la asistencia sanitaria por parte de otros colectivos que se hallan en una situación especial, como las personas privadas de libertad en centros penitenciarios ${ }^{68}$. Podrían sufrir enfermedades crónicas

62 STEDH de 27 de mayo de 2008, asunto 25565/05, N. vs. Reino Unido, apdos. 44-50. Véase también Pérez Alberdi (2014): 328-330.

63 STEDH de 15 de febrero de 2002, asunto 46553/99, SCC vs. Suecia, apdo. 3, no admitida la demanda.

64 STEDH de 29 de mayo de 1998, asunto 40900/98, Karara vs. Finlandia, apdo. 4, no admite la demanda.

65 STEDH de 7 de julio de 2015, asunto 60125/11, V. M. y otros vs. Bélgica, apdos. 142-160. Se declaró la violación del art. 3 del Convenio por la falta de asistencia y de proveer un alojamiento digno a todas esas personas, incluso pese a reconocerse la saturación del sistema de atención a las personas que solicitan asilo.

66 Wolff (2012): 96-101.

67 Lasagabaster Herrarte y Angoitia Gorostiaga (2015: 49). También existe algún otro caso en que el TEDH pone de manifiesto la falta de medios para proceder a la intervención quirúrgica.

68 STEDH de 25 de mayo de 2014, Asunto 19696/10, Gheorghe Predescu vs. Rumania, apdos. 51-56. En este caso, no se acertó en el diagnóstico médico respecto a la situación de una persona enferma mental en un centro penitenciario. La estrategia 
o progresivas y, pese a su condición de presidiarias, las autoridades públicas se encuentran obligadas a proporcionarles el tratamiento médico adecuado ${ }^{69}$.

En caso de que se produzca una deficiencia en la atención médica, los Estados han de prever remedios legales disponibles para aclarar los hechos, determinar los responsables y proveer los medios de reparación necesarios para la víctima. Las autoridades deben efectuar un intento serio para averiguar qué sucedió empleando los medios disponibles para asegurar la evidencia de todo aquello que afectó al incidente ${ }^{70}$. Las obligaciones de acción positivas también deben imponerse a las autoridades públicas cuando se trata del cuidado y asistencia de menores, especialmente si se trata de personas discapacitadas ${ }^{71}$. En fin, en la sanidad pública los Estados deben aprobar un cuadro reglamentario que imponga a los hospitales, sean públicos o privados, la adopción de medidas propias para asegurar la protección de la vida de sus pacientes ${ }^{72}$.

terapéutica ha de ser la adecuada, que ha de limitar los efectos de la enfermedad o prevenir su agravación (STEDH de 16 de abril de 2015, asunto 63054/2013, Papastavrou $v$ s. Grecia, apdo. 89). La atención médica en las prisiones debe adquirir estándares propios de una persona que no se halla privada de libertad. La atención adecuada y la diligencia de las autoridades internas también debe aplicarse en los casos en que se produzca el ingreso en el servicio militar (STEDH de 6 de octubre de 2015, asunto 17081/06, Metin Gültekin y otros vs. Turquía, apdos. 47 y 48). Asimismo, se estima la violación del art. 3 por no atender a tiempo a un enfermo de cáncer que se encontraba cumpliendo condena en prisión (STEDH de 13 de octubre de 2016, Asunto 31928/15, Konovalchuk vs. Ucrania, apdos. 55-62).

69 STEDH 3 de mayo de 2009, asunto 23052/05, Kaprykowsky vs. Polonia, apdos. 69-78. En concreto, un ciudadano polaco que padecía epilepsia fue encarcelado en una penitenciaría del Estado. Asimismo, se le habían diagnosticado otros males psicóticos, úlceras estomacales y sífilis. Los prisioneros deben ser detenidos en condiciones compatibles con el respeto a la dignidad humana y las medidas restrictivas impuestas por las autoridades no deben exceder, en cuanto a su intensidad, del grado inevitable de sufrimiento que conlleva la detención.

70 STEDH de 16 de enero de 2014, asunto 6318/03, Valerie Fuklev vs. Ucrania, apdos. 93-98. En relación con el derecho a la vulneración del derecho a la vida, puede citarse también la STEDH de 17 de julio de 2014, Asunto 47848/08, Valentin Campeanu vs. Rumania, apdos. 140-143.

71 STEDH de 19 de febrero de 2015, asunto 10401/12, Helhal vs. Francia, apdos. 62 y 63. La persona minusválida padecía incontinencia urinaria y no se le facilitó un acceso digno a los servicios sanitarios, lo que suponía un trato humillante o degradante.

72 SSTEDH de 18 de junio de 2013, Asunto 48609/2006, Nencheva y otros vs. Bulgaria, apdos. 117-129 y 13 de noviembre de 2012, asunto 30015/96, A. y otros vs. Turquía, apdos. 82-87. 


\subsection{Medio ambiente}

La ecología implica la modificación de modelos de pensar, así como de comportamientos. Pone atención en la salvaguarda de la diversidad de las especies en equilibrio con el comportamiento humano. El medio ambiente es al mismo tiempo el medio natural, la inserción del hombre en dicho medio y el medio humano, y el patrimonio de la humanidad ${ }^{73}$. Diferentes resoluciones del TEDH y el TC han puesto de manifiesto el vínculo que une el medio ambiente y la vida digna de las personas, pues influye sensiblemente en bienes jurídicos como la salud o la integridad física ${ }^{74}$. Asimismo, el Comité de Derechos Sociales (CDS), en aplicación de la Carta Social Europea, ha examinado diversos supuestos en que se les obligaba a las autoridades públicas a adoptar medidas para prevenir posibles daños a la salud de la ciudadanía, procedentes de actividades humanas con impacto ambiental, como el depósito o tratamiento de residuos o las emisiones al medio ambiente ${ }^{75}$.

Desde las primeras resoluciones emanadas del TEDH, la clave para reconocer la vulneración del derecho a la vida privada y familiar consistió en que el Estado debía garantizar el justo equilibrio entre el bienestar económico de la ciudad y el disfrute del derecho a la vida privada y familiar ${ }^{76}$. Debe exigirse a las autoridades públicas que minimicen, hasta donde sea posible, la injerencia en estos derechos, intentando encontrar soluciones alternativas y buscando alcanzar los fines de la forma menos onerosa para los derechos humanos ${ }^{77}$. Para lograr esto, deben llevar a cabo una investigación y un estudio adecuado y completo con objeto de encontrar la mejor solución posible que lleve a un equilibrio entre los intereses en conflicto ${ }^{78}$. Se han dictado fallos que se refieren al tráfico de vehículos, cuyo ruido y perturbaciones

\footnotetext{
Breton (2003: 14).

Morte Gómez y Salinas Alcega (2009: 408 y 409).

75 Entre otras, Resolución CDS de 23 de enero de 2013 (Demanda 72/2011), respecto al vertido de sustancias químicas a un río en la región de Oynofita en Grecia, imputándole a este estado la responsabilidad por no adoptar medidas que permitan reducir la polución de una forma medible.

76 STEDH de 9 de diciembre de 1994, asunto 16798/1990, López Ostra vs. España, apdo. 58.

77 Sudre (2012: 550).

78 STEDH de 2 de octubre de 2001, asunto 36022/1997, Hatton y otros vs. Reino Unido, apdo. 97. Véase Arzoz Santisteban (2015: 377). No se efectuó una ponderación justa de los intereses de la comunidad, por un lado, y el interés privado consistente en disfrutar efectivamente de los derechos reconocidos en el art. 8.1 CEDH. Cita, acerca de este particular, el asunto Fedeyeva vs. Rusia en Sentencia de 4 de junio de 2015.
} 
vulneran el derecho a la vida privada y familiar. Las autoridades del municipio de Budapest adoptaron medidas, pero no resultaron suficientes y proporcionadas para evitar las molestias ${ }^{79}$. El TEDH no solo reprocha la carencia de legislación, sino también la omisión de medidas de control e intervención ante la persistencia de la infracción de las normas, por ejemplo, en materia de ruido ${ }^{80}$.

Piénsese que no es imprescindible demostrar un perjuicio actual, sino que bastaría con la potencialidad del peligro ${ }^{81}$. El incumplimiento de las normas de protección y mitigación del impacto ambiental avalan ese riesgo. Así, los daños provocados por la actividad minera durante quince años habían mermado sensiblemente el modo de vida de la población, cuya subsistencia dependía de explotaciones agropecuarias de pequeña escala ${ }^{82}$. La tolerancia de las actividades con perjuicios ambientales y a la salud de las personas se castiga especialmente en caso de que suceda algún accidente o catástrofe, como la pérdida de la vivienda ${ }^{83}$.

Respecto a la jurisprudencia del TC, cabe reseñar que en alguna controversia ha vinculado los niveles excesivos de ruido o contaminación acústica a la vulneración, no solo del derecho a la intimidad, sino también a la integridad física. Así, exige que los niveles de ruido superen el umbral a partir del cual se ponga en grave peligro inmediato la salud. Ahora bien, pese a que expresamente parece acoger la doctrina de la Corte europea, todo ello no

79 STEDH de 9 de noviembre de 2010, asunto 2345/2006, Dees vs. Hungría, apdos. 21-23.

80 STEDH 16 de noviembre de 2004, asunto 4143/2002, Moreno Gómez vs. España, apdos. 59-61. Respecto a esta cuestión, véase, también, STEDH de 20 de mayo de 2010, asunto 61260/2008, Oluic vs. Croacia, apdos. 63-65. En este caso, se reprocha por el TEDH el retraso en la adopción de medidas que condujeran a permitir unos niveles de ruido emitidos por un bar situado en un edificio destinado a residencia. STEDH de 2 de noviembre de 2006, Giacomelli vs. Italia, apdos. 67 y 68. En este caso se trataba de una planta de residuos muy próxima a viviendas. Un ejemplo de la falta de supervisión de la actividad sucede cuando las autoridades internas no verifican el cumplimiento de la evaluación de impacto ambiental durante un periodo de tiempo, lo que acrecienta el riesgo de empeoramiento de la salud y calidad de vida de las personas. STEDH de 4 de septiembre de 2014, asunto 42488/02, Dzemyuk vs. Ucrania, apdos. 91 y 92 .

81 Arzoz Santisteban (2015: 376).

82 STEDH de 10 de febrero de 2011, asunto 30499/03, Dubetska y otros vs. Ucrania, apdos. 152-155.

83 STEDH de 30 de noviembre de 2004, asunto 48939/99, Öneryildiz vs. Turquía, apdos. 127-135. 
supone una traslación mimética de sus sentencias, lo que supondría ignorar las diferencias normativas existentes entre la CE y el Convenio Europeo de Derechos Humanos $^{84}$. La vulneración del derecho fundamental no se deriva del incumplimiento de los umbrales, sino en el efectivo o potencial perjuicio a la vida o la salud de las personas.

Además, en una sentencia más reciente, señala el TC que el recurso de amparo no es el medio idóneo para enjuiciar si la Administración permitió con su pasividad que en una zona acústicamente saturada se superasen los umbrales fijados por la ordenanza ni si esa pasividad prolongada fue el origen de una notable degradación medioambiental, sino solamente si esa omisión impidió el disfrute del derecho fundamental alegado, dada la intensidad y permanencia de los ruidos. No debe pronunciarse, por tanto, a su juicio, acerca de la calidad de vida existente en el entorno urbano de su vivienda, sino exclusivamente si el derecho a la intimidad se ha vulnerado ${ }^{85}$.

De este modo, el TC escinde el incumplimiento de la legalidad, por constituir una infracción administrativa, de la vulneración de un derecho fundamental, lo cual requiere algo más que superar umbrales y que, directamente, se obstaculice el ejercicio de un derecho fundamenta ${ }^{86}$. Además, han de tomarse en consideración circunstancias objetivas y subjetivas que demuestren el ataque a los derechos, como la situación del edificio, el aislamiento de su fachada, el tipo de habitación (interior o exterior) o la incidencia nocturna del ruido ${ }^{87}$.

Expresada en esos términos la doctrina del TC, se expresó un voto particular cuyo eje estribaba en que el fallo se había apartado del caso Moreno Gómez, en tanto que en la sentencia del TEDH no se había precisado prueba alguna acerca del efecto concreto del ruido en la vivienda y no se exigía una prueba individualizada, al aportar las mismas autoridades evidencias suficientes que acreditaban la dimensión del ruido. Además, como se ha comentado, en alguna sentencia, el TEDH calificó de insuficientes las medidas adoptadas por las autoridades públicas, lo cual significa que la vulneración puede proceder, no ya de una omisión exclusivamente - como parece desprenderse de la doctrina del TC—, sino de una actuación incorrecta. Por todo ello, los magistrados discrepantes sostenían la vulneración del art. 10.2 CE al no ajustarse las

\footnotetext{
84 STC 16/2004, FJ 3. .

85 STC 150/2011, FJ 6.․

86 Véase la STC 119/2001, FJ 6.․ La superación de los umbrales ha de impedir o dificultar gravemente el libre desarrollo de la personalidad, siempre que la lesión proceda de actos u omisiones públicos a los que sea imputable la lesión producida.

87 Idem, FJ 8. . Véase Díaz Crego (2012: 45 y 46).
} 
autoridades internas a la interpretación de los Convenios y Tratados Internacionales suscritos por España ${ }^{88}$. Cierto es que el mismo TEDH consideró insuficientes determinadas pruebas en alguna controversia ${ }^{89}$.

Expuestas las sentencias, no se acierta a comprender por qué, desde una perspectiva interna o internacional, no se asume la incidencia de los factores ambientales y el estado de los elementos del medio físico en la vida de las personas, siquiera en un incierto largo plazo ${ }^{90}$. En algunos países de Latinoamérica se les considera derechos susceptibles de ser protegidos en amparo constitucional, incluso mediante instancias jurisdiccionales internacionales, como la Corte Interamericana de Derechos Humanos ${ }^{91}$. En Francia, se ha aprobado por una ley constitucional la Carta del Medio Ambiente, lo que blinda de algún modo los principios y previsiones en ella reconocidos ${ }^{92}$.

\subsection{Vivienda}

Buena parte de las controversias en esta materia deriva de los desalojos forzosos a los que se han visto sometidos colectivos de raza gitana que habitaban en asentamientos apartados de zonas residenciales comunes de las urbes. En la controversia suscitada en el municipio de Patras (Grecia), el Comité de Derechos Humanos de la ONU consideró vulnerados varios artículos del Pacto Internacional de derechos Civiles y Políticos, en concreto, los referidos al derecho a un juicio justo y el derecho a la intimidad y a la vida privada de

88 STC 150/2011. Voto formulado por el magistrado Luís Ortega, al que se adhirieron los otros magistrados Eugeni Gay y Elisa Pérez Vera. A todo ello, cabría añadir una omisión por parte del TC en el análisis de la controversia: la ausencia de un test de proporcionalidad entre los bienes jurídicos e intereses implicados y la necesidad de alcanzar un equilibrio entre los mismos. Si hubieran llevado a cabo el test, podría deducirse que el medio ambiente es un derecho y no tanto un principio que requiere desarrollo legislativo. No parecería cohonestarse con el texto constitucional, pese a que los poderes públicos han de atenerse a la interpretación de los Tratado y Convenios, como normas incorporadas al derecho interno.

89 STEDH de 1 de julio de 2008, asunto 71146/2001, Borysiewicz vs. Polonia apdos. 53-55. Véase, también, STEDH de 22 de noviembre de 2011, asunto 24202/2010, Zammit Maempel vs. Malta, apdos. 68-73.

90 Courtis (2007: 58).

91 Véase, como ejemplo, la Sentencia CIDH, de 27 de junio de 2012, Pueblo Indígena Kichwa de Sarayaku vs. Ecuador, especialmente apdos. 188-196.

92 Ruiz-Rico Ruiz (2007): 22. 
las personas ${ }^{93}$. Se les exigió a las autoridades griegas proveer a estos grupos de recursos efectivos, así como una indemnización que compensase los daños causados. Asimismo, en algún voto particular se afirmaba abiertamente la necesidad de vincular los derechos sociales del Pacto con los derechos fundamentales, de modo que deberían considerarse todos ellos indivisibles, universales e interdependientes ${ }^{94}$.

El TEDH, por su parte, se ha mostrado más proclive a interpretaciones restrictivas del derecho a la vida privada y familiar. En ocasiones, ha considerado prioritarias las previsiones urbanísticas que pueden establecer las autoridades públicas internas en caso de que los asentamientos se hallen ubicados en zonas no residenciales ${ }^{95}$. Si hubieran establecido las viviendas en ámbitos en los que se permitiera la edificación, las autoridades deberían adoptar las medidas tendentes a permitir el ejercicio de su derecho a la vivienda ${ }^{96}$. Además, el TEDH exige que sea un órgano jurisdiccional independiente el que resuelva en torno a la prohibición de ocupar una vivienda o a su desalojo ${ }^{97}$ y debe establecerse la posibilidad de recurrir la decisión jurisdiccional que examine las circunstancias del desahucio ${ }^{98}$.

El reconocimiento del derecho a la vivienda siempre se vincula a las circunstancias subjetivas de la persona que pide su reconocimiento ${ }^{99}$. En ese sentido, la petición prioritaria no consiste en exigir una indemnización por

93 Escobar Roca y González González (2012: 1352 y 1353).

94 Dictamen CDH de 14 de septiembre de 2010, Comunicación 1799/2008, Georgopoulos vs. Grecia, apdos. 7-10. Véase, también, Consejo De Europa (2012: 137-140).

95 STEDH de 18 enero de 2011, asunto 27238/95, Chapman vs. Reino Unido, apdos. 112-115. Cuenta con votos particulares que aducen la aplicación del art. 8, debido a que el Estado no adoptó las medidas necesarias de realojo e impidió el desarrollo libre de la personalidad a toda una comunidad de personas.

96 STEDH de 27 de septiembre de 1997, asunto, 31417/96, Lustig-Prean and Becket vs. Reino Unido, apdos. 80-81.

97 STEDH de 13 de mayo de 2008, asunto 10999/04, McCann vs. Reino Unido, apdos. 49-55. Véase, también, SSTEDH de 21 de septiembre de 2010, asunto 37341/06; Kay y otros vs. Reino Unido, apdos. 71-74; y el precedente STEDH de 27 de mayo de 2004, asunto 66746/01, Connors vs. Reino Unido, apdos. 86-95. Al respecto, véase Casadevall (2012: 350 y 351).

98 STEDH de 18 de diciembre de 2012, asunto 40060/08, Buckland vs. Reino Unido, apdos. 70-72. Si bien se había producido la suspensión del acuerdo de toma de posesión, lo cierto es que no se habilitó un recurso que evaluase la proporcionalidad de la medida.

99 Palmer (2009: 78). 
los daños causados, sino que la persona afectada ha de manifestar su voluntad para continuar habitando la vivienda a la que no se le permite acceder o ha sido desalojado ${ }^{100}$. Las condiciones de un desalojo pueden aplicarse correctamente conforme a la legislación interna, lo que no conlleva en sí mismo que la medida resulte necesaria y proporcionada. Los desahucios pueden ajustarse a las previsiones legislativas y garantizar la seguridad jurídica, así como, si se trata de una vivienda protegida, el bienestar de aquellas personas que la utilizan legalmente. Sin embargo, la intervención pública mediante un desahucio ha de ser necesaria en una sociedad democrática, lo que requiere un examen caso por caso de las circunstancias que rodean el desalojo. En un caso, por ejemplo, la vivienda protegida que había sido objeto de desahucio no se transfirió a otras personas para su uso - en garantía de su objeto social-, sino que la conservó el Estado con fines especulativos, sin apreciar el especial apego que mantenían los anteriores ocupantes ${ }^{101}$. Este vínculo específico con el entorno y la vivienda también se invoca en caso de que se trate de personas que han perdido la vivienda por su condición de desplazadas en un conflicto bélico ${ }^{102}$.

La interpretación del derecho a la vida privada y familiar ha de tomarse en consideración de forma prioritaria al afectar a la identidad del individuo, su autodeterminación e integridad física y moral ${ }^{103}$; a las relaciones con otras personas; y, por último, al mantenimiento de un lugar seguro y estable. Otro de los factores que parece valorar de modo favorable el TEDH es el apego especial a la vivienda que la persona había demostrado, denostando intentos de especulación ${ }^{104}$. En definitiva, resulta indispensable evaluar las

100 STEDH de 27 de mayo de 2010, asunto 6518/2004, Dokic vs. Bosnia Herzegovina, apdo. 66.

101 STEDH de 29 de enero de 2015, asunto 15711/13, Stolyarova vs. Rusia, apdos. 59-63. Tampoco se molestó el Gobierno ruso en facilitar otra vivienda para el realojo que, incluso, podría haberse producido en Moscú, tal y como señala el Tribunal.

102 STEDH de 16 de junio de 2015, asunto 13216/05, Chiragov y otros vs. Armenia, apdos. 206-208.

103 Tomás Mallén (2011: 292).

104 STEDH de 6 de diciembre de 2011, asunto 7097/10, Gladysheva vs. Rusia, apdos. 93-97. Los procesos de privatización de las viviendas o del patrimonio público, como consecuencia del tránsito a un sistema de libre mercado, ocasionaban situaciones de desamparo y de enorme inseguridad jurídica en Rusia. De hecho, no se cumplían las condiciones legales para el acceso a una vivienda e, incluso, pesaba una acusación de falsedad documental sobre la ocupante del inmueble, en el cumplimiento de los requisitos para mantener su vivienda y que no fuera vendida por el gobierno ruso. Al respecto, véase, también, STEDH de 21 de junio de 2011, asunto 48833/07, Orlic vs. 
circunstancias personales y familiares para resolver la proporcionalidad y necesidad de un desahucio ${ }^{105}$.

Una de las formas de solucionar los problemas de ponderación consiste en el planteamiento de alternativas que eviten el desalojo, de manera que se presente como solución de última ratio $^{106}$. Eso puede conllevar el realojo, recabar la colaboración de las autoridades públicas u ofrecer ayudas económicas. Esta puede ser una forma de paliar las dificultades familiares que entraña la imposibilidad de permanecer en una vivienda ${ }^{107}$. Si la privación de la vivienda entraña la separación de los hijos de sus padres, el TEDH entiende esto como una injerencia de los poderes públicos en la vida privada y familiar de las personas. El Estado debería actuar, a juicio del TEDH, de manera que permita que el vínculo familiar perviva y se desenvuelva con normalidad, adoptando las medidas necesarias para reunir al padre y al hijo en cuestión ${ }^{108}$. Así, se les reprochó a las autoridades checas la decisión de internar a los niños en centros de menores y no buscar otras alternativas, como la concesión de ayudas sociales; la búsqueda de empleo a los padres que les permitieran disfrutar de una mayor estabilidad económica; o la asistencia para solicitar una vivienda social ${ }^{109}$.

Croacia, apdos. 68-71. En este caso, se pone de manifiesto el vínculo que une al recurrente con la comunidad. Se afirma que el interés del Estado en controlar la legalidad es secundario respecto al derecho de la persona a que se respete su hogar. En el mismo sentido, véase STEDH de 13 de septiembre de 2016, asunto 75737, Andrey Medvedev vs. Rusia, apdos. 55 y 56. Pese a que podría aplicarse la ley para ceder la vivienda a otras personas que figuraban en la lista para su venta, lo cierto es que debe valorarse el apego o el vínculo que le unía a la anterior pareja con el entorno donde vivían.

105 Sudre (2012: 540).

106 Leckie (2001: 155).

107 STEDH de 22 de febrero de 2005, asunto 47148/1999, Novoseletsky vs. Ucrania, apdos. 75-88. Un matrimonio había abandonado voluntariamente la vivienda para trasladarse a otra zona del país a fin de culminar los estudios uno de los cónyuges. Eso significó también el desplazamiento con su esposa, quien tuvo un hijo durante los dos años de estancia fuera del hogar. Las autoridades, al comprobar la ausencia de los ocupantes por un período prolongado de tiempo, decidió adjudicar la vivienda a otras personas, plantear alternativa alguna para los que habían desocupado la vivienda.

108 Jiménez García (2014: 116).

109 STEDH de 26 de octubre de 2006, asunto 23848/2004, Wallová y Walla vs. República Checa, apdos. 67-78. Asimismo, véase STEDH de 16 de junio de 2015, asunto 40167/06, Sargsyan vs. Azerbayán, apdos. 259-262. Al respecto, en situaciones 
Sucede algo parecido cuando el TEDH excluye cualquier tipo de injerencia en las competencias internas y, sin embargo, enjuicia y examina si las medidas adoptadas para proveer vivienda a unas personas son proporcionales para garantizar su vida privada y familiar, además de proponer alternativas antes de emplear ese recurso excepcional que es el desahucio ${ }^{110}$. En ese mismo sentido, la Corte exigió al Estado que adoptara medidas efectivas para realojar a un exconvicto cuya vivienda protegida había sido transmitida a un tercero de buena $\mathrm{fe}^{111}$. Pese a tratarse de una decisión de inequívoca competencia interna, las cuestiones económicas, el derecho de propiedad y la libertad de empresa deben ceder ante la extensión del derecho a la vida privada y familiar. Ahora bien, podría preguntarse en qué medida el estado se encuentra obligado al realojo o adoptar otro tipo de medidas si se carece de los recursos indispensables para ello. El TEDH en esa hipótesis entiende que, una vez reconocido el derecho, incluso por la vía jurisdiccional no puede justificarse el incumplimiento de una sentencia ejecutiva por la escasez de recursos en materia de vivienda ${ }^{112}$.

Todo ello permite concluir que no puede descartarse la protección y tutela del derecho a la vivienda y más en la situación actual, en que continúa privándoseles de su hogar a muchas familias. La cuestión es el alcance del derecho a la vida privada y familiar en materia de vivienda, habida cuenta del excesivo casuismo que se desprende de la jurisprudencia analizada. Asimismo, cabe cuestionarse por qué se excluye una buena parte de la población que no responde a los criterios fijados por el TEDH. ¿Acaso no son titulares del mencionado derecho a la vida privada y familiar?

\section{LAS CONSECUENCIAS JURÍDICAS EN EL DERECHO ESPAÑOL}

\section{LA APLICABILIDAD DIRECTA Y LAS MEDIDAS DE ACCIÓN POSITIVA}

La intervención pública no debe ir dirigida exactamente a garantizar a todas las personas una vivienda o la asistencia sanitaria, entre otras razones

extremas de conflictos bélicos, el Estado ha de encontrar alternativas para impedir que se prive a las víctimas del conflicto del derecho a la vida privada y familiar.

110 Jiménez García (2014: 117).

111 STEDH de 20 de octubre de 2016, asunto 34000/07, Vinniychuk vs. Ucrania, apdos. 48-52.

112 STEDH de 9 de abril de 2015, asunto 65829/12, Tchokontio Happi vs. Francia, apdo. 50. El derecho controvertido en este caso es el referido al juicio justo (art. 6 $\mathrm{CEDH})$. 
porque las demandas y peticiones indiscriminadas cuentan con límites de difícil superación, como los recursos económicos, las exigencias medioambientales o urbanísticas. No obstante, todo ello no significa que deba soslayarse la virtualidad de aquella expansión ${ }^{113}$. Lo que está proponiendo en último término la jurisprudencia del TEDH o, incluso, del Comité de derechos humanos de la ONU es un test de proporcionalidad, lo que comporta no ignorar el medio ambiente o las demandas de las personas que están expuestas a vivir a la intemperie. Las autoridades públicas han de ponderar los derechos e intereses en presencia, incluida su capacidad para satisfacer las peticiones o resolver los conflictos que puede suscitar el estado de salud de una persona o la carencia de vivienda en algunos supuestos.

La premisa que proponen hoy las autoridades públicas no consiste en ignorar el debate, sino en otorgar preferencia a uno de los elementos en conflicto, en concreto, la viabilidad económica, cuyos perfiles y medidas para lograrla no los define en muchas ocasiones el gobierno de los estados, sino instituciones internacionales vinculadas a la estabilidad financiera. A ese factor debe sumarse la peligrosa tendencia a la autorregulación como mecanismo para modular los derechos humanos, sobre todo en el ámbito laboral ${ }^{114}$.

La interpretación expansiva de los derechos fundamentales debe provocar una reflexión en torno al debate suscitado por las instancias jurisdiccionales internacionales y los mecanismos empleados por ellas para resolver la colisión de derechos ${ }^{115}$. En ese sentido, las autoridades internas deben tomar en consideración estas tesis no solo en el momento de decidir respecto a controversias particulares, como, por ejemplo, los desahucios o la petición de asistencia sanitaria, sino también para aprobar normas y disposiciones que vayan precedidas del balance o ponderación de derechos e intereses de acuerdo con el principio de proporcionalidad ${ }^{116}$. Todo ello permitiría dotar progresivamente a los principios rectores y a los llamados derechos sociales de un acervo y contenido que ha de considerarse irreductible e irreversible. La casuística jurisprudencial puede servir para recoger todo ese desarrollo en normas e

113 López Guerra (2014: 316).

114 Faría (2001: 130).

115 Gordillo Pérez (2014: 47).

116 Para el TC alemán, las previsiones de la norma enjuiciada relativas a las prestaciones estándar no respetaban el art. 1.1 (Estado social) en conexión con el art. 20.1 (dignidad humana) a la hora de garantizar el mínimo de subsistencia que la dignidad de la persona requiere. Así, el derecho fundamental a la garantía de un mínimo vital debe asegurar — decía el Tribunal — a toda persona necesitada las condiciones materiales indispensables para su existencia y para la participación en la vida social. 
instrumentos vinculantes que gocen de mayor estabilidad y procuren seguridad jurídica ${ }^{117}$. La acción positiva de los poderes públicos debe basarse en esos criterios interpretativos.

\section{LA NECESIDAD DE ATENDER LA DOCTRINA POR PARTE DE LOS ÓRGANOS JURISDICCIONALES ESPAÑOLES}

Con arreglo al art.10.2 CE, las normas relativas a los derechos fundamentales y a las libertades que la $\mathrm{CE}$ reconoce, han de interpretarse de conformidad con los tratados y acuerdos internacionales sobre estas que hayan sido ratificados por España, como la Declaración Universal de Derechos Humanos. Este es el anclaje en el ordenamiento interno que tendrían las sentencias del TEDH o dictámenes de la Comisión de Derechos Humanos de la ONU ${ }^{118}$. Estas últimas instancias son las que interpretan el alcance de los derechos reconocidos en los instrumentos internacionales y, por tanto, aunque sea por la vía jurisprudencial, vinculan los poderes públicos internos ${ }^{119}$. Las decisiones de la Comisión y las sentencias de la Corte europea obtienen de esta manera un impacto que va mucho más allá de la simple resolución del caso individual ${ }^{120}$. Aun así, no siempre se han trasladado con acierto estas tesis por parte de las autoridades españolas.

En alguna sentencia comentada, en la que se abordaban cuestiones ambientales, el TC vaciló en cuanto a la aplicación de la doctrina del TEDH en torno a las inmisiones que pudieran afectar a la vida privada y familiar de las personas. El argumento consistía en que los derechos reconocidos en el $\mathrm{CEDH}$ pueden albergar un contenido más amplio que el derecho a la intimidad reconocida como tal en el texto constitucional y conforme a la doctrina del TC. A ese argumento cabe oponer que, por la vía indirecta, aquel debe velar por la aplicación del art. 10.2 CE, de cuyo enunciado se desprende la necesidad de que el contenido de los derechos fundamentales sea acorde o compatible con la legislación internacional en esa materia ratificada por España. Todos estos requisitos se ajustan a los contenidos que prevén el $\mathrm{CEDH}$ o al PDCP, en tanto en cuanto forman parte del ordenamiento interno.

\footnotetext{
117 Bon (2006: 142).

118 Jimena Quesada (2006: 68).

119 Cambot (2006: 125).

120 Lezertua Rodríguez (1990: 1280-1282).
} 
Asimismo, los fallos del TC adolecen de ciertas carencias en el análisis de la jurisprudencia del TEDH. En reciente sentencia, relativa a diversos desalojos en asentamientos del extrarradio de las ciudades, no se examinan sentencias de la Corte europea que dirimen una controversia relacionada con los desahucios prescindiendo de la legalidad. Los magistrados disidentes criticaron la ausencia de explicación en torno a la necesidad de la medida de intervención, la falta de alternativas que eviten una invasión tan excesiva en el derecho de una persona, además de una posible quiebra del principio de confianza legítima, al haberse tolerado por la Administración el uso del suelo en un periodo de tiempo ${ }^{121}$.

En ese mismo asunto, el TEDH valoró de forma positiva el hecho de que el Ayuntamiento de Madrid no procedió automáticamente a decretar los desalojos durante las negociaciones. Asimismo, admitió la Corte europea la adopción de diferentes medidas con el fin de proporcionar estabilidad a los demandantes y al resto de los habitantes afectados durante las negociaciones, colaborando en la lucha contra los problemas en la Cañada Real ${ }^{122}$. De todo ello puede llegar a deducirse que incluso las autoridades públicas no aplicaron de forma inmediata la legalidad, al objeto de acudir a otras alternativas más proporcionadas y razonables.

El entronque con la cláusula del Estado social y la mutua potenciación de ambos principios ahonda en la igualdad de oportunidades para toda persona por medio de la redistribución de la renta ${ }^{123}$. Para ello, la misma cláusula del Estado social o los principios rectores en sí mismos deberían adquirir una dimensión propia y una efectividad directa y desligada de la concreción exigida habitualmente por el TC. Esta tesis se encuentra respaldada por los vínculos e interacciones que se generan con derechos fundamentales $\mathrm{y}$, asimismo, por el sentido que se le debe otorgar a la dignidad de la persona como fundamento del orden político y de la paz social (art. 10.1 CE) ${ }^{124}$.

Podría afirmarse, igualmente, que esos mismos principios rectores reciben progresivamente un desarrollo por organismos como el Comité Europeo

121 STC $188 / 2013$, FJ $4 .^{\circ}$ y $5 .^{\circ}$. Los votos particulares fueron firmados por los magistrados Fernando Valdés y Adela Asúa. Se trataba del desalojo de una zona llamada La Cañada Real Galiana, situada en Madrid, en la que desde los años sesenta se han ido construyendo asentamientos complemente fuera de la ordenación urbanística. Al tratarse de numerosas viviendas o infraviviendas afectadas, el Ayuntamiento decidió suspender la ejecución durante las negociaciones.

122 STEDH de 15 de enero de 2015, asunto 3537/2013, Mohamed Raji y otros vs. España, apdos. 24 y 25.

123 García Macho (2009: 76).

124 Escobar Roca (2012: 364). 
de Derechos Sociales que elabora recomendaciones a los Estados en relación con el efectivo reconocimiento de los derechos contemplados en la Carta Social Europea y los protocolos que la complementan ${ }^{125}$. El Estado español no ha ratificado uno de ellos, que dedica su articulado a la concreción de los derechos sociales. No obstante, los poderes públicos españoles no pueden ignorar los pronunciamientos del Comité Europeo, toda vez que este contribuye a colmar vacíos y lagunas interpretativas de las cuales, en el plano de la concreción, adolece la Carta Social Europea ${ }^{126}$. En ese sentido, la influencia y efectos de este acervo jurisprudencial se refiere al contenido de los derechos, pero no puede olvidarse el cauce o método que las instancias internacionales emplean para dirimir las controversias en caso de colisión de derechos ${ }^{127}$.

\section{LA ACTUACIÓN DE LOS PODERES PÚBLICOS EN LA PONDERACIÓN DE LOS DERECHOS EN PRESENCIA}

Ante la colisión de los derechos, y a efectos de encuadrar la tesis que se expone, en primer lugar, debe establecerse la conexión entre el derecho fundamental y el derecho social o la prestación que debe llevar a cabo el Estado ${ }^{128}$. Puede identificarse el supuesto de hecho mediante el empleo de la analogía, examinando los hechos y la correspondiente calificación jurídica que ha realizado el TEDH o el CDH de la ONU. Sin esa conexión previa, es decir, si no se ha podido establecer el paralelismo, no podría invocarse el derecho a la intimidad, a la integridad física y, por tanto, de lege ferenda las pretensiones de reconocimiento del derecho quedarían enormemente mermadas. En segundo término, debe abordarse el test de la proporcionalidad desde una triple perspectiva: la idoneidad de la regulación interna, es decir, si se ajusta a los fines establecidos por el ordenamiento interno; su necesidad, en el sentido de que

125 Courtis (2007: 34). Los estándares internacionales servirían como modo de concreción del derecho social en cuestión.

126 Véanse, entre otras, Resolución de 24 de enero de 2012, Reclamación 64/2011, European Roma and Travellers Forum vs. Francia; R. de 5 de diciembre de 2007, Reclamación 39/2006, Federación Europea de Organizaciones del Trabajo con los sin techo vs. Francia, apdos. 34-36; R. 30 de marzo de 2009, Reclamación 45/2007, Interights vs. Croacia, apdos. 43-50; R. 11 de septiembre de 2012, Reclamación 67/2011, Médicos del Mundo Internacional vs. Francia, apdo. 26. Véase Jiménez García (2009: 6-12).

127 Jimena Quesada (2007: 69).

128 Pisarello (2007: 65). 
la actuación pública se encuentra justificada en atención a las necesidades básicas que deben satisfacerse ${ }^{129}$; y tres, las medidas aplicadas por las instituciones internas no deben provocar la anulación o extinción de los derechos e intereses en colisión o su minoración excesiva, para lo cual deben estudiarse los medios alternativos que permitan una articulación o conciliación de los derechos en la mayor medida de lo posible. Este es el sentido más estricto de la proporcionalidad que exige una auténtica labor de ponderación ${ }^{130}$.

La ponderación podría definirse como un mandato de optimización entre los principios. Cuanto mayor es el grado de incumplimiento o de afectación de un principio tanto mayor tiene que ser la importancia del cumplimiento del otro. Debería establecerse como prioridad los derechos del individuo, de modo que no pueda ser restringido el derecho individual en caso de que existan dudas (in dubio pro libertate) ${ }^{131}$. Es característico de todos los modelos de ponderación que el contenido de los derechos prima facie es mayor que el contenido de los derechos definitivos. Dicho de otra forma, los deberes del Estado correlativos a esos derechos son inferiores a los deberes definitivos ${ }^{132}$.

En esa labor de complementación o adecuación de los derechos o intereses, alguno de ellos pierde parte de su contenido para ceder ante el contenido esencial del resto de bienes y derechos en conflicto. Eso significa que no podría establecerse una jerarquía entre los principios de forma previa a la ponderación ${ }^{133}$. Incluso, la cláusula del Estado social debe situarse en el mismo plano respecto al Estado de derecho y al democrático ${ }^{134}$. Sin embargo, en el caso del desalojo de viviendas, las personas están sujetas a esa falta de seguridad y estabilidad que conlleva su situación jurídica precaria. La clave radica en otorgar a los Estados y autoridades públicas el mayor poder para gestionar los recursos escasos y distribuir equitativamente la riqueza y asistir a las personas que se encuentran excluidas precisamente por la escasez de recursos que sufren ${ }^{135}$. No podría ignorarse esa intervención previa de los poderes públicos, primero,

129 Escobar roca (2012: 370).

130 Rodríguez de Santiago (2000: 107-111).

131 Alexy (1997: 207).

132 Carmona Cuenca (2006: 1797).

133 Bernal Pulido (2007: 393). Cuanto más importante sea una determinada posición para que el derecho fundamental pueda desempeñar su función de defensa, su función democrática y su función de derecho de prestación, mayor será el peso que debe otorgarse al derecho fundamental en la ponderación, cuando dicha posición sea afectada por Ley (p. 773).

134 Escobar Roca (2012: 364).

135 Eide (2001: 26). 
por la vía legislativa y, después por la administrativa o jurisdiccional. En esos supuestos debe exigirse una labor de ponderación entre los bienes y derechos en presencia, sin que prevalezcan unos sobre otros en el análisis a priori.

En la ponderación deben examinarse no solo las circunstancias fácticas, sino también la interpretación y alcance de las normas ${ }^{136}$, incluso las que podrían calificarse de soft law, porque dibujan un patrón de comportamiento. Cuando se emplea el término interés, las obligaciones parecen más difusas o ambiguas, sin embargo la ponderación de los principios, derechos o valores en pie de igualdad conduce a la obtención de resultados más satisfactorios para alcanzar la dignidad de la persona ${ }^{137}$. Prevaler el derecho de propiedad, la libertad de empresa o el cumplimiento de los contratos y no examinar todos los intereses o derechos en conjunto, incluidos los efectos perjudiciales en otros derechos, como el de la vida privada o familiar, significa ignorar la dignidad de la persona como valor supremo del ordenamiento jurídico ${ }^{138}$.

La interpretación del derecho por el juez no consiste únicamente en la interpretación de la ley sobre la base de un procedimiento puramente lógico: aunque no sea consciente de ello, el juez, para alcanzar una decisión, debe elegir y, para ello, debe introducir siempre valoraciones personales que no están vinculadas al esquema legislativo que él debe aplicar ${ }^{139}$. La satisfacción de los derechos sociales se basa en la dignidad de la persona y en los niveles mínimos de subsistencia que garantizan la misma. Esa es la principal condición del sentido de pertenencia y solidaridad social en que se basan la cohesión y los vínculos prepolíticos invocados como esenciales por las teorías comunitarias ${ }^{140}$.

\section{CONCLUSIONES}

Primera. La teoría liberal de los derechos fundamentales debe entenderse superada atendiendo al contexto actual en que han de ser reconocidos y amparados. Los índices de desigualdad muestran signos negativos, y los poderes públicos no pueden ignorar esta realidad acogiéndose a clasificaciones o categorías de derechos que se hallan inevitablemente ligadas, si no subsumidas

136 García Amado (2009: 324 y 325).

137 Medina Guerrero (1996: 63).

138 Rorty (1998: 132). Seguridad como condiciones de vida suficientemente libres de riesgo como para que las diferencias con los demás resulten irrelevantes para la autoestima y para la dignidad personal.

139 Bobbio (1993: 241).

140 Ferrajoli (2001: 292). 
completamente, en un concepto, como es el de la dignidad de la persona, la cual incluye su autonomía y libertad. Este es el corolario de la interdependencia y universalidad de los derechos humanos que alzaprima por encima de cualquier concepto o categoría el de la persona y su libre desenvolvimiento en sociedad.

Segunda. La aplicabilidad directa de principios como el derecho a la vivienda digna, la asistencia sanitaria o el medio ambiente no puede someterse a los vaivenes del mercado o al color de la fuerza política dominante. Poseen eficacia y virtualidad propias, fundamentalmente porque su contenido se halla estrechamente vinculado a la integridad física, a la vida personal y familiar o, en general, a la dignidad. El concepto de derecho subjetivo clásico no puede servir como fundamento exclusivo para la exigibilidad a las administraciones de determinadas prestaciones o servicios. Mediante la vía pretoriana se ha elaborado una rica casuística que ha permitido concretar o precisar, en función de las circunstancias objetivas o subjetivas, qué puede exigirse a la ciudadanía o a los poderes públicos.

Tercera. La jurisprudencia del TEDH no ha reconocido un derecho a la vivienda a todas las personas o a la asistencia sanitaria universal, sino que ha fijado unos criterios o cauces para que las autoridades públicas internas actúen, adopten medidas en relación con la efectividad de aquellos derechos sociales, en determinadas circunstancias. De todo ello se desprende, por un lado, que la misma jurisprudencia ha rechazado una interpretación rígida y hermética de los derechos fundamentales; $y$, por otro, que ha sido sensible a las actuales necesidades sociales, como aquella familia quebrada por un desahucio, originadas por una visión excesivamente economicista o patrimonialista, pergeñada por teorías neoliberales subyugadas a intereses económicos.

Cuarta. Las instituciones internas deben hacer efectivos los pronunciamientos de las jurisdicciones internacionales a través de las decisiones emanadas de los tres poderes, fundamentalmente el legislativo. La interpretación de los tratados internacionales, operada por aquellas, vincula a los poderes públicos como si se tratara de una parte del ordenamiento interno. Las cuestiones de legalidad interna no pueden resultar incompatibles con el derecho internacional, so pena de generar inseguridad jurídica y falta de coherencia, lo que precisamente pretendió evitarse incorporando al derecho interno el contenido de los tratados. Todo ello significa que, del mismo modo que el TEDH aplicó el principio de proporcionalidad para valorar en qué medida resulta necesaria una decisión interna que impida disfrutar de un medio ambiente adecuado o de una vivienda digna, el legislador y, en consecuencia, la jurisdicción deben ponderar los derechos e intereses en presencia cuando trate de dirimir una controversia de este tipo. Incluso, podrían obligar a administraciones o jueces a adoptar medidas que conduzcan a afectar en la menor medida de lo posible a aquellos bienes jurídicos, también llamados derechos sociales. 
Quinta. La competitividad, la eficiencia, la sostenibilidad en el gasto, siendo valores nada desdeñables y ciertamente necesarios, no deben primar sobre la dignidad de la persona, su libre desarrollo, su autonomía y, en consecuencia, también su libertad. En ese sentido, las propuestas legislativas deberían partir de esa ponderación entre los derechos patrimoniales de las empresas para funcionar, o de los propietarios que pretenden disfrutar de sus viviendas o de los acreedores hipotecarios, y aquellos que corresponden a personas que no pueden perder su dignidad, su derecho a la vida personal o a su integridad física. En un Estado social y democrático de derecho no debe establecerse la prevalencia de unos valores que sustentan un sistema económico cuyo desarrollo se está mostrando inicuo y doloroso para buena parte de las personas.

\section{Bibliografía}

Abramovich, V. y Courtois, C. (2004): Los derechos sociales como derechos exigibles. Madrid: Trotta.

Alexy, R. (1995). Teoría del discurso y derechos humanos. Bogotá: Universidad Externado de Colombia. (1997). El concepto y la validez del derecho. Barcelona: Gedisa.

Añón Roig, M. J., De Lucas, J. et al. (2004). Lecciones de derechos sociales, Valencia: Tirant lo Blanch.

Arruego, G. (2009). Derechos fundamentales y biomedicina: algunas reflexiones acerca del derecho a la integridad en la doctrina del TC y del TEDH. En A. Embrid Irujo (dir.). Derechos económicos y sociales (pp. 271-304). Madrid: Iustel.

Arzoz Santisteban, X. (2015). Art. 8. Derecho al respeto a la vida privada y familiar. En I. Lasagabaster Herrarte (dir.), Convenio Europeo de Derechos Humanos. Comentario Sistemático (pp. 377-397). Madrid: Civitas/Thomson- Reuters.

Bernal Pulido, C. (2007). El principio de proporcionalidad y los derechos fundamentales. Madrid: Centro de Estudios Políticos y Constitucionales.

Bobbio, N. (1993). El positivismo jurídico. Madrid: Debate.

Bon, P. (2006). Les droits sociaux fondamentaux en Espagne : le régime. En L. Gay, E. Mazuyer y D. Nazet-Allouche (dirs.). Les droits sociaux fondamentaux. Entre droits nationaux et droit européen (pp. 135-148). Paris: Bryllant.

Breton, J. M. (2003). Du droit de l'environnement au droit á l'environnement : quête humaniste et odyssée normative. En J. Ferrand y H. Petit (dirs.). Enjeux et perspectives des droits de l'homme (pp. 14-24). Grenoble : L'Harmattan.

Cambot, P. (2006). Les droits sociaux fondamentaux en Espagne : la notion. En L. Gay, E. Mazuyer y D. Nazet-Allouche (dirs.). Les droits sociaux fondamentaux. Entre droits nationaux et droit européen (pp. 117-134). Paris: Bryllant.

Carmona Cuenca, E. (2006). Los derechos sociales de prestación y el derecho a un mínimo vital. Nuevas Politicas Públicas. Anuario Multidisciplinar para la Modernización de las Administraciones Públicas, 5, 173-197. 
Casadevall, J. (2012). El Convenio Europeo de Derechos Humanos, el Tribunal de Estrasburgo y su jurisprudencia. Valencia: Tirant lo Blanch.

Corriente Córdoba, J. A. (2000). La protección de los derechos económicos, sociales y culturales en la Carta de Derechos Fundamentales de la Unión Europea. Anuario de Derecho Europeo, 2, 128-132.

Courtois, C. (2007). Derechos sociales, ambientales y relaciones entre particulares. Nuevos horizontes. Bilbao: Universidad de Deusto.

De Lora, P. y Zúñiga Fajuri, A. (2009). El derecho a la asistencia sanitaria. Un análisis desde las teorías de la justicia distributiva. Madrid: Iustel.

Díaz Crego, M. (2012). Derechos sociales y amparo constitucional. Revista Vasca de Administración Pública, 95, 17-57.

Donnelly, J. (2013). Universal human rights in theory and practice. London: Cornell University Press.

Durán y Lalaguna, P. (2007). La perspectiva de las Naciones Unidas en la protección de los derechos sociales. Cizur Menor (Navarra): Thomson/Aranzadi.

Eide, A. (2001). Economic, social and cultural rights. En A. Eifr, C. Krause y A. Rosas (eds.). Economic, social and cultural rights. A textbook. Dordrecht: Kluwer Law International.

- (2001). The right to an adequate standard of living. En A. Eifr, C. Krause y A. Rosas (eds.). Economic, social and cultural rights. A textbook. Dordrecht: Kluwer Law International.

Escobar Roca, G. (2012). Los derechos fundamentales sociales de prestación (doctrina general). En G. Escobar Roca (dir.). Derechos sociales y tutela antidiscriminatoria (pp. 459648). Cizur Menor (Navarra): Thomson Reuters-Aranzadi.

- (2012). El derecho a la protección de la salud. En G. Escobar Roca (dir.). Derechos sociales y tutela antidiscriminatoria (pp. 1076-1084). Cizur Menor (Navarra): Thomson Reuters-Aranzadi.

— y González González, B. (2012). El derecho a la vivienda. En G. Escobar Roca (dir.). Derechos sociales y tutela antidiscriminatoria (pp. 1271-1293). Cizur Menor (Navarra): Thomson Reuters-Aranzadi.

Faría, J. E. (2001). El derecho en la economía globalizada. Madrid: Trotta.

Fernández, E. (1984). Teoría de la justicia y derechos humanos. Madrid: Debate.

Ferrajoli, L. (2001). Los fundamentos de los derechos fundamentales. Madrid: Trotta.

Ferrari, V. (1989). Funciones del derecho. Madrid: Debate.

García Amado, J. A. (2009). El juicio de ponderación y sus partes. Una crítica. En R. García Manrique (ed.). Derechos sociales y ponderación (pp. 249-326). Madrid: Fundación Coloquio Jurídico Europeo.

García Macho, R. (2009). Los derechos fundamentales sociales y el derecho a una vivienda como derechos fundamentales de libertad. Revista Catalana de Dret Public, 39, 67-96.

García Schwarz, R. (2011). Derechos sociales: imprescindibilidad y garantías. Cizur Menor (Navarra): Thomson-Reuters.

Gavara de Cara, J. C. (2010). La dimensión objetiva de los derechos sociales. Barcelona: Bosch. González Amuchastegui, J. (2004). Autonomía, dignidad y ciudadanía. Una teoría de los Derechos Humanos. Valencia: Tirant lo Blanch. 
Gordillo Pérez, L. I. (2014). Derechos sociales y austeridad. Lex Social. Revista Jurídica de los Derechos Sociales, 4 (1), 34-55.

Gregg, B. (2013). Human Rights as social construction. Cambridge: Cambridge University Press. Habermas, J. (2002). Teoría y praxis. Estudios de filosofía social. Madrid: Tecnos.

Jimena Quesada, L. (2006). Retos pendientes del Estado social español: en especial, la ratificación de la Carta Social Europea revisada de 1996. Nuevas Políticas Públicas: Anuario Multidisciplinar para la Modernización de las Administraciones Públicas, 2, 40-71.

- (2007). La jurisprudencia del Comité Europeo de Derechos sociales (Sistema de Reclamaciones Colectivas), vol. I. Valencia: Tirant lo Blanch.

- (2012). El derecho a los servicios sociales. En G. Escobar Roca (dir.). Derechos sociales y tutela antidiscriminatoria (pp. 1508-1525). Cizur Menor (Navarra): Thomson Reuters-Aranzadi.

Jiménez García, F. (2014). Tomarse en serio el derecho internacional de los derechos humanos. Especial referencia a los derechos sociales, el derecho a la vivienda y la prohibición de los desalojos forzosos. Revista Española de Derecho Constitucional, 101, 79-124.

Kinley, D. (2009). Civilising globalisation. Human rights and the global economy. Cambridge: Cambridge University Press. Disponible en: https://doi.org/10.1017/CBO9780511803710.

Kleimt, H. (1979). Filosofía del Estado y criterios de legitimidad. Buenos Aires: Alfa.

Lasa López, A. (2012). Los derechos sociales en el constitucionalismo de mercado: aporías de la dimensión social de la Unión Europea. Bilbao: Universidad del País Vasco.

Lasagabaster Herrarte, I. y Angoitia Gorostiaga, V. (2015). Art. 2. Derecho a la vida. En I. Lasagabaster Herrarte (dir.). Convenio Europeo de Derechos Humanos. Comentario Sistemático (pp. 45-54). Madrid: Civitas-Thomson- Reuters.

Rodríguez, M. L. (1990). Los derechos sociales fundamentales y el Convenio europeo de derechos humanos. Relaciones laborales: Revista Crítica de Teoría y Práctica, 2, 1276-1296.

López Guerra, L. (2014). La protección de derechos económicos y sociales en el Convenio europeo de Derechos Humanos. En M. J. Terol Becerra y L. Jimena Quesada (coords.). Tratado sobre protección de derechos sociales (pp. 312-316). Valencia: Tirant lo Blanch.

Marks, S. P. (2010). Human rights and development. En S. Joseph y A. McBeth (eds.). Research Handbook on International Human Rights Law (pp. 69-75). Cheltenham: Edward Elgar. Disponible en: https://doi.org/10.4337/9781849803373.00012.

McBeth, A. (2010). Human rights in economic globalization. En S. Joseph y A. McBeth (eds.). Research Handbook on International Human Rights Law (pp. 142-149). Cheltenham: Edward Elgar.

Medina Guerrero, M. (1996). La vinculación negativa del legislador a los derechos fundamentales. Madrid: McGraw-Hill.

Morte Gómez, C. y Salinas Acelga, S. (2009). Los derechos económicos y sociales en la jurisprudencia del Tribunal Europeo de Derechos Humanos. En A. Embrid Irujo (dir.). Derechos económicos y sociales (pp. 359-415). Madrid: Iustel.

Moreno González, B. (2002). El Estado social. Naturaleza jurídica y estructura de los derechos sociales. Madrid: Civitas. 
Nazet-Allouche, D. (2006). La Cour de justice des Communautés européennes et les droits sociaux fondamentaux. En L. Gay, E. Mazuyer y D. Nazet-Allouche (dirs.). Les droits sociaux fondamentaux. Entre droits nationaux et droit européen (pp. 215-232). Paris: Bryllant.

Nino, C. S. (1989). Ética y derechos humanos. Un ensayo de fundamentación, Barcelona: Ariel.

Noguera Fernández, A. (2014). El fin de la cultura de los derechos: Unión Europea post-Maastricht y transformaciones en el Estado constitucional. Derechos y Libertades, 30, 43-70.

Ordóñez Solís, D. (2006). La protección judicial de los derechos fundamentales de solidaridad. derechos sociales, medio ambiente y consumidores. Granada: Comares.

Palmer, E. (2009). Judicial review, socio-economic rights and the Human Rights Act. Portland: Hart Publishing.

Pérez Alberdi, R. (2014). La protección de los derechos sociales en la jurisprudencia del TEDH. En M. J. Terol Becerra y L. Jimena Quesada (coords.). Tratado sobre protección de derechos sociales (pp. 318-328). Valencia: Tirant lo Blanch.

Pérez Luño, A. E. (2010). Derechos Humanos, Estado de Derecho y Constitución, Madrid: Tecnos.

Pisarello, G. (2007). Los derechos sociales y sus garantías. Elementos para una reconstrucción. Madrid: Trotta.

Rawls, J. (1998). El derecho de gentes. En S. Shute y S. Hurley. (eds.). De los derechos humanos. Madrid: Trotta.

Rawls, J. (1979). Teoría de la justicia. Madrid: Ediciones F. C. E.

Rodríguez de Santiago, J. M. (2007). La administración del estado social. Madrid: Marcial Pons.

- (2000). La ponderación de bienes e intereses en el derecho administrativo. Madrid: Marcial Pons.

Rorty, R. (1998). Derechos humanos, racionalidad y sentimentalidad. En S. Shute y S. Hurley. De los derechos humanos (pp. 19-133). Madrid: Trotta.

Ruiz-Rico Ruiz, G. (2007). La constitucionalización del derecho al medio ambiente en Francia: principios y derechos de la Charte de l'environnement. En J. M. Ruiz-Rico Ruiz, G. Ruiz-Rico Ruiz y N. Pérez Sola (coords.). Derecho ambiental. Análisis jurídico y económico de la normativa medioambiental de la Unión Europea y española: estado actual y perspectivas de futuro (pp. 21-28). Valencia: Tirant lo Blanch.

Santamaría Arinas, R. J. y Bolaño Piñeiro, M. (2015). Art. 3. Prohibición de la tortura. En I. Lasagabaster Herrarte (dir.). Convenio Europeo de Derechos Humanos. Comentario Sistemático (pp. 77-86). Madrid: Civitas-Thomson- Reuters.

Sudre, F. (2012). Droit Européen et international des droits de l'homme. Paris: PUF.

Tomás Mallén, B. (2011). El derecho a la protección de la salud o a la asistencia sanitaria a la luz de la Ley 12/2009, de 30 de octubre, reguladora del derecho de asilo y de la protección subsidiaria. En M. J. Terol Becerra (dir.). IV Foro Andaluz de los Derechos Sociales. Igualdad e Integración (pp. 286-308). Valencia: Tirant lo Blanch.

Torres del Moral, A. (2014). El Estado social y la evolución del constitucionalismo social. En M. J. Terol Becerra y L. Jimena Quesada (coords.). Tratado sobre protección de derechos sociales (pp. 61-65). Valencia: Tirant lo Blanch.

Triguero Martínez, L. A. (2012). Los derechos sociales fundamentales de los trabajadores inmigrantes. Granada: Comares.

Uvin, P. (2004). Human rights and development. Bloomfield: Kumarian Press. 